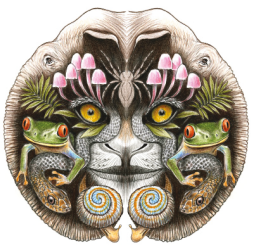

ISSN

Online 0974-7907

Print 0974-7893

\title{
COPROLOGICAL PREVALENCE OF GASTROINTESTINAL PARASITES IN CARNIVORES AND SMALL MAMMALS AT DHAKA ZOO, BANGLADESH
}

OPEN ACCESS

\author{
M.M. Rokib ur Raja ${ }^{1}$, Anita Rani Dey ${ }^{2}$, Nurjahan Begum ${ }^{3}$, Uzzal Kumar Kundu ${ }^{4}$
} \& Faishal Al Ashad ${ }^{5}$

1,2,3,4 Department of Parasitology, Faculty of Veterinary Science, Bangladesh Agricultural University, Mymensingh 2202,

Bangladesh.

${ }^{5}$ Department of Youth Development, Ministry of Youth and Sports, Chadpur 3600, Bangladesh ${ }^{1}$ rakib.raja@gmail.com, ${ }^{2}$ anitadey.dpp.vet@gmail.com (corresponding author), 3 nurjahanpara@yahoo.com, ${ }^{4}$ dvmuzzal2010@gmail.com, ${ }^{5}$ drfaishal@yahoo.com

Abstract: A study on the coprological prevalence of gastrointestinal parasites using 94 faecal samples from different carnivores $(n=32)$ and small mammals $(n=15)$ was undertaken from January to May 2012 at Dhaka Zoo. The overall prevalence of parasitic infection was $78.72 \%$, with a prevalence of $51.06 \%$ for helminths and $27.66 \%$ for protozoa. The identified parasites included-Toxascaris leonina (9.57\%), Balantidium coli (25.53\%) Spirometra sp. (10.64\%), Toxocara cati (12.76\%), Hook worm (4.26\%), unidentified strongyles (3.19\%), Trichuris sp. (7.45\%), Coccidia sp. (2.12\%), Capillaria sp. (1.06\%), Trichostrongylus sp. (1.06\%), and Physaloptera sp. (1.06\%). Mixed infection was observed in Indian Lion (Toxascaris leonina and Spirometra sp.), Royal Bengal Tiger (Balantidium coli and Toxocara cati ), Spotted Hyena (Balantidium coli and hook worm), Leopard (Balantidium coli and Spirometra sp.), Rhesus Macaque (Trichuris sp. and Coccidia sp.), Pig-tailed Macaque (Balantidium coli and Trichuris sp.), Hamadryas Baboon (Balantidium coli and Trichuris sp.), Golden Mangabey (Trichuris sp., Balantidium coli and unidentified strongyles), Large Indian Civet (Balantidium coli and unidentified strongyles), Torior Dog (Balantidium coli and Physaloptera), Rabbit (Balantidium coli and Hook worm), Hanuman Langur (Balantidium coli and Capillaria sp.). Due to the high prevalence of gastrointestinal parasites, the present study suggests to apply control measures against these parasites in order to safeguard the health of housed wild animals, especially in case of threatened species.

Keywords: Carnivores, coprology, gastrointestinal parasites, prevalence, small mammals.
Zoological gardens exhibit wild animals for aesthetic, educational and conservation purposes (Varadharajan \& Pythal 1999). The main aim of zoological gardens is to preserve rare and endangered species. Parasitic diseases constitute one of the major problems and causes of mortality in these animals (Rao \& Acharjyo 1984). In nature, wild animals range accross large areas and have consequently a low genetic resistance against parasitic infections because of low exposure. When herds of these wild animals are kept in a relatively small space in zoological gardens, the problem of various parasitic infections can aggravate and pose a serious threat to endangered species, occasionally causing sudden and unexpected local declines in abundance (Muoria et al. 2005). The occurrence of parasites in animals housed in zoos varies according to the husbandry practices, disease prophylaxis and treatment administered. Inadequate information on diseases and parasites of zoo animals is a major limiting factor in adopting prophylactic measures in zoological gardens. Investigations regarding endoparasitic fauna are important for the study of the prevalence, geographical distribution, systematics and biology of parasites (Zasityte \& Grikienciene 2002).

DOI: http://dx.doi.org/10.11609/JoTT.03569.5574-9 | ZooBank: urn:Isid:zoobank.org:pub:E6451C8F-244E-46C3-ABEA-DFD7455A4362

Editor: Ulrike Streicher, Wildlife Veterinarian / Wildlife Management Consultant, Danang, Vietnam.

Date of publication: 26 March 2014 (online \& print)

Manuscript details: Ms \# 03569 | Received 27 March 2013 | Final received 16 March 2014 | Finally accepted 17 March 2014

Citation: Raja, M.M.R.U., A.R. Dey, N. Begum, U.K. Kundu \& F.A. Ashad (2014). Coprological prevalence of gastrointestinal parasites in carnivores and small mammals at Dhaka zoo, Bangladesh. Journal of Threatened Taxa 6(3): 5574-5579; http://dx.doi.org/10.11609/JoTT.03569.5574-9

Copyright: @ Raja et al. 2014. Creative Commons Attribution 3.0 Unported License. JoTT allows unrestricted use of this article in any medium, reproduction and distribution by providing adequate credit to the authors and the source of publication.

Funding: Department of Parasitology provided fund for this research.

Competing Interest: The authors declare no competing interests.

Acknowledgements: We thank the respected teachers in the Department of Parasitology and also the authority of the Dhaka Zoo. 
Over the years, research on gastro-intestinal parasites has been carried out on Common Mole, Cane Rat, Gorilla, birds in captivity (e.g., Chaunha et al. 1973), reptiles, ungulates and many zoo animals across the globe (e.g., Kumar et al. 2005; Singh et al. 2006).

A regular program of gastrointestinal parasite surveillance and control measures like effective treatment and proper prophylaxis based on correct diagnosis would certainly improve the health situation in zoo animals.

Considering these facts, the present study was undertaken to identify the gastrointestinal parasites and determine their prevalence based on morphometry and count of developmental stages in faecal samples from carnivores and small mammals of Dhaka Zoo.

\section{Materials and Methods}

This study was conducted at Dhaka Zoo from January to May 2012. The zoo houses many native and non native animals and wildlife.

Selection of animals: The study included the carnivores, non human primates and several small mammal species. Ninety-four samples were collected of which 70 were from carnivores including Indian Lion (24), Tiger (20), Hyena (4), Asiatic Black Bear (4), Dingo Dog (2), Ratel (2), Fox (2), Fishing Cat (2), Leopard (4), Binturong (2), Large Indian Civet (2), Torior Dog (2), 18 from non human primates including Rhesus Macaque (2), Pig-tailed Macaque (2), Hanuman Langur (2), Hamadryas Baboon (2), Vervet Monkey (2), Olive Baboon (4), Hoolock Gibbon (2), Golden Mangabey (2), and Guinea Pig (2), Rabbit (2) and Indian-crested Porcupine (2).

Collection and preservation of samples: Individual faecal samples were collected with the help of each animal's caretakers in the early morning. After collection the faecal sample was placed in a polythene bag containing $10 \%$ formalin. Then the opening edge of the bag was tightly tied with ribbon to avoid contamination and each sample was marked according to species.

Coprological examination: Samples were examined at the laboratory of the Department of Parasitology, Bangladesh Agricultural University, Mymensingh. The sample was processed for microscopic examination. The ova, cysts, oocysts and larvae of different parasites were tentatively identified according to the morphology and then quantitative estimation was done by applying the Stoll's ova dilution technique and McMaster technique to determine eggs per gram (EPG), cysts per gram (CPG) and oocysts per gram (OPG) of faeces as described by Soulsby (1982).
Morphological measurements of ova and cysts: The egg or cyst or oocysts were finally identified based on measurements (length and width) by using a micrometer as described by Cable (1965).

\section{Results}

Overall prevalence of gastrointestinal parasites: The overall prevalence of parasitic infection was $78.72 \%$ (74/94), of which $51.06 \%$ (48) were helminthic and $27.66 \%$ (26) were protozoan infections (Fig. 1). The identified parasites included protozoa (Balantidium coli, Coccidia sp.), helminths (Toxascaris leonina, Spirometra sp., Toxocara cati, Hook Worm, Trichuris sp., Capillaria sp., unidentified strongyles, Trichostrongylus sp. and Physaloptera sp.). The results indicated that helminthic infections were more common than protozoan infections in carnivores and small mammals.

The prevalence and intensity of different gastrointestinal parasites: Prevalence of identified parasites was $-9.57 \%$ for Toxascaris leonina, $25.53 \%$ for Balantidium coli, $10.64 \%$ for Spirometra sp., $12.76 \%$ for Toxocara cati, $4.26 \%$ for Hook worm, 3.19\% for unidentified strongyles, 7,45\% for Trichuris sp., 2.12\% for Coccidia sp., 1.06\% for Capillaria sp., 1.06\% for Trichostrongylus sp. and $1.06 \%$ for Physaloptera sp. (Table 2). The mean of OPG, CPG, and EPG was calculated for all the animal species and the ranges are shown in Table 1. The highest EPG was found in Leopard for Spirometra sp. as 6200. The intensity in EPG of other parasites was 1500 for Toxascaris leonina, 800 for Coccidia sp., 500 for Trichostrongylus sp., 400 for Capillaria sp. and 400 for Trichuris sp.

Prevalence of mixed infection: Mixed infection was observed in 12 species including Indian Lion (Toxascaris leonina and Spirometra sp.), Royal Bengal Tiger (Balantidium coli and Toxocara cati), Spotted Hyena (Balantidium coli and Hook Worm), Leopard (Balantidium

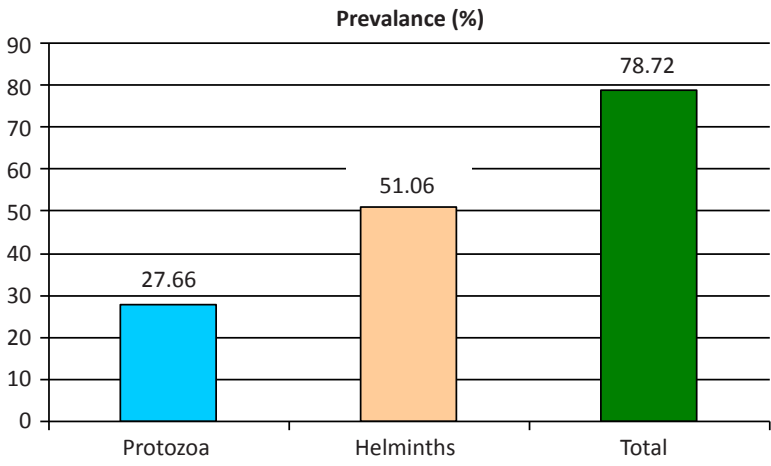

Figure 1. Overall prevalence of parasitic infection in carnivore and small mammals at Dhaka Zoo. 
Table 1. Prevalence and intensity of ova/cyst/oocysts of different parasites in different animals at Dhaka Zoo

\begin{tabular}{|c|c|c|c|c|}
\hline \multirow{2}{*}{ Common Name } & \multirow{2}{*}{ Name of the parasite } & \multirow{2}{*}{$\begin{array}{l}\text { No. of positive case } \\
\text { (No. of sample) }\end{array}$} & \multirow{2}{*}{$\begin{array}{c}\text { Prevalence } \\
\text { (\%) }\end{array}$} & $\begin{array}{c}\text { Intensity of infection(EPG } \\
/ \text { CPG)/(OPG) }\end{array}$ \\
\hline & & & & Ranges \\
\hline \multirow{3}{*}{ Indian Lion } & Toxascaris leonina & $9(24)$ & 37.5 & $1200-1500$ \\
\hline & Spirometra sp. & $5(24)$ & 20.83 & $800-1000$ \\
\hline & Balantidium coli & $3(24)$ & 12.5 & $300-400$ \\
\hline \multirow{2}{*}{ Royal Bengal Tiger } & Toxocara cati & $12(20)$ & 60 & $1200-1400$ \\
\hline & Balantidium coli & $3(20)$ & 15 & $300-400$ \\
\hline \multirow{2}{*}{ Spotted Hyena } & Hook worm & $1(2)$ & 50 & $600-800$ \\
\hline & Balantidium coli & 1(2) & 50 & $300-400$ \\
\hline \multirow{2}{*}{ Striped Hyena } & Balantidium coli & 1(2) & 50 & $600-800$ \\
\hline & Hook worm & $2(2)$ & 100 & 800 \\
\hline Asiatic Black Bear & Balantidium coli & $1(4)$ & 25 & $300-400$ \\
\hline Dingo Dog & Spirometra sp. & $1(2)$ & 50 & $800-1000$ \\
\hline Rattle & Balantidium coli & $1(2)$ & 50 & $600-800$ \\
\hline Bengal Fox & Balantidium coli & $2(2)$ & 100 & $600-800$ \\
\hline Fishing Cat & Nil & $0(2)$ & 0 & - \\
\hline \multirow{2}{*}{ Leopard } & Balantidium coli & $2(4)$ & 50 & $600-800$ \\
\hline & Spirometra sp. & $4(4)$ & 100 & $4800-6200$ \\
\hline Indian-crested Porcupine & Nil & $0(2)$ & 0 & - \\
\hline Guinea Pig & Nil & $0(2)$ & 0 & - \\
\hline \multirow{2}{*}{ Rhesus Monkey } & Trichuris sp. & $2(2)$ & 100 & $300-400$ \\
\hline & Coccidia & $1(2)$ & 50 & $600-800$ \\
\hline Pig-tailed Macaque & Trichuris sp. & $1(2)$ & 50 & $300-400$ \\
\hline \multirow{2}{*}{ Hanuman Langur } & Balantidium coli & 1(2) & 50 & $300-400$ \\
\hline & Capillaria sp. & $1(2)$ & 50 & $300-400$ \\
\hline \multirow{2}{*}{ Hamadryas Baboon } & Trichuris sp. & $2(2)$ & 100 & $600-800$ \\
\hline & Balantidium coli & 1(2) & 50 & $300-400$ \\
\hline \multirow{3}{*}{ Rabbit } & Balantidium coli & $2(2)$ & 100 & $300-400$ \\
\hline & Hook worm & 1(2) & 50 & 400 \\
\hline & Coccidia & 1(2) & 50 & $600-800$ \\
\hline Vervet Monkey & Nil & $0(2)$ & 0 & - \\
\hline Bingturong & Nil & $0(2)$ & 0 & - \\
\hline \multirow{2}{*}{ Olive Baboon } & Trichostrongylus sp. & $1(4)$ & 50 & 500 \\
\hline & Balantidium coli & $1(4)$ & 50 & $600-800$ \\
\hline \multirow{2}{*}{ Hoolock Gibbon } & Balantidium coli & 1(2) & 50 & $800-1000$ \\
\hline & Trichuris sp. & $1(2)$ & 50 & 400 \\
\hline \multirow{3}{*}{ Golden Mangabey } & Trichuris sp. & $1(2)$ & 50 & 400 \\
\hline & Balantidium coli & 1(2) & 50 & $800-1000$ \\
\hline & Unidentified strongyles & 1(2) & 50 & 300 \\
\hline \multirow{2}{*}{ Large Indian Civet } & Stomach worm & $2(2)$ & 100 & 300 \\
\hline & Balantidium coli & $1(2)$ & 50 & $800-1000$ \\
\hline \multirow{2}{*}{ Torior Dog } & Balantidium coli & $2(2)$ & 100 & $600-800$ \\
\hline & Physaloptera sp. & $1(2)$ & 50 & 300 \\
\hline
\end{tabular}


coli and Spirometra sp.), Rhesus Macaque (Trichuris sp. and Coccidia sp.), Pig-tailed Macaque (Balantidium coli and Trichuris sp.), Hamadryas Baboon (Balantidium coli and Trichuris sp.), Golden Mangabey (Balantidium coli, unidentified strongyles and Trichuris sp.), Large Indian Civet (Balantidium coli and unidentified strongyles), Torior Dog (Balantidium coli and Physaloptera sp.), Rabbit (Balantidium coli and hook worm), Hanuman Langur( Balantidium coli and Capillaria sp.) (Table 3).

Sizes of eggs and cysts of different gastrointestinal parasites in different animals: The sizes (length by width) in $\mu \mathrm{m}$ of eggs, cysts and oocysts of different gastrointestinal parasites were measured (Table 4, Images 1-6).

\section{Discussion}

In this study we found $78.72 \%$ of the faceal samples infected with parasites. This result is similar to the earlier report of Corden et al. (2008) and Opara et al. (2010) who revealed $72.5 \%$ respectively $76.6 \%$ positive cases. Higher prevalences were found by Mutani et al. (2003), who reported $88.7 \%$ postitive samples from Barbados. In contrary much lower prevalences were found by Stuart et al. (1990), who only found $48 \%$ of the animals were infected with parasites in Costa Rica. However, both these studies are conducted on primates, do not include carnivores and small mammals and are furthermore conducted on free ranging animals and not in a captive setting. But they illustrate that both higher and lower prevalences of parasite infections can be found even in free ranging animals.

The prevalence of helminthic infection (52.06\%) was found higher than protozoan infection $(27.66 \%)$. In this the present study differs from the report of Parasani et al. (2001) who revealed $68.8 \%$ animals positive for helminthic infections and $18.8 \%$ for protozoan infections in Rajkot Municipal Corporation Zoo. Both studies were conducted in a captive setting and included a variety of animal groups. The difference in findings demonstrates that even under a similar setup, parasite prevalences might still be very different due to different geographic conditions, management practices, animal food sources and other influences. In non human primates, the isolated parasities included Trichuris sp., Balantidium coli and unidentified strongyles, with Balantidium coli having the highest prevalence. Trichuris sp. has often been recorded in primates (Mutani et al. 2003; Kimberley et al. 2004; Corden et al. 2008; Lim et al. 2008; Singh et al. 2009) and Balantidium coli has been previously reported by Leveck et al. (2007).

In this study, Royal Bengal Tigers were found to be
Table 2. Prevalence of parasites in different animals at Dhaka zoo

\begin{tabular}{|l|l|c|c|}
\hline $\begin{array}{l}\text { Types of } \\
\text { parasites }\end{array}$ & Name of the parasites & $\begin{array}{c}\text { No. of } \\
\text { positive case }\end{array}$ & $\begin{array}{c}\text { Prevalence } \\
\text { (\%) }\end{array}$ \\
\hline \multirow{4}{*}{ Protozoa } & Balantidium coli & 24 & 25.53 \\
\cline { 2 - 4 } & Coccidia & 02 & 2.12 \\
\hline \multirow{4}{*}{ Nematode } & Toxocara cati & 12 & 12.77 \\
\cline { 2 - 4 } & Capillaria sp. & 01 & 1.06 \\
\cline { 2 - 4 } & Trichuris sp. & 07 & 7.45 \\
\cline { 2 - 4 } & Toxascaris leonina & 09 & 9.57 \\
\cline { 2 - 4 } & Hook worm & 04 & 4.26 \\
\cline { 2 - 4 } & Unidentified Strongyles & 03 & 3.19 \\
\cline { 2 - 4 } & Trichostrongylus sp. & 01 & 1.06 \\
\cline { 2 - 4 } & Physaloptera sp. & 01 & 1.06 \\
\hline \multirow{4}{*}{ Cestode } & Spirometra sp. & 10 & 10.64 \\
\hline
\end{tabular}

Table 3. Prevalence of mixed infection

\begin{tabular}{|l|c|c|}
\hline Name of the parasites & No. of case & $\begin{array}{c}\text { Prevalence } \\
\text { (\%) }\end{array}$ \\
\hline Balantidium coli and Toxocara cati & 05 & 5.31 \\
\hline $\begin{array}{l}\text { Balantidium coli and Unidentified } \\
\text { strongyles }\end{array}$ & 01 & 1.06 \\
\hline Balantidium coli and hook worm & 02 & 2.12 \\
\hline Balantidium coli and Spirometra sp. & 02 & 2.12 \\
\hline Balantidium coli and Trichuris sp. & 02 & 2.12 \\
\hline Balantidium coli and Capillaria sp. & 01 & 1.06 \\
\hline Toxascaris leonina and Spirometra sp. & 01 & 1.06 \\
\hline Balantidium coli and Physaloptera sp. & 01 & 1.06 \\
\hline Trichuris sp. and Coccidia & 01 & 1.06 \\
\hline $\begin{array}{l}\text { Balantidium coli and unidentified } \\
\text { strongyles and Trichuris sp. }\end{array}$ & 01 & 1.06 \\
\hline
\end{tabular}

Table 4. The size of ova/cysts/oocysts of different parasites

\begin{tabular}{|l|c|}
\hline Name of the parasites & Size of ova/cyst/larvae/oocyst $(\mu \mathrm{m})$ \\
\hline Toxascaris leonina & $72.5 \times 43.5$ \\
\hline Spirometra sp & $58 \times 29$ \\
\hline Toxocara cati & $72.5 \times 72.5$, \\
\hline Unidentified strongyles & $72.5 \times 43.5$ \\
\hline Trichostrongylus sp., & $72.5 \times 43.5$ \\
\hline Physaloptera sp. & $45 \times 30$ \\
\hline Trichuris sp. & $58 \times 29$ \\
\hline Coccidian oocysts & $43.5 \times 29$ \\
\hline Balantidium coli & $43.5 \times 29$ \\
\hline
\end{tabular}

infected with Toxocara cati. The occurrence of $T$. cati in this species has already been reported by Fagiolini et al. (2010) and Gonzalez et al. (2007). Lion were infected with Toxascaris leonina, Spirometra sp. and Balantidium 


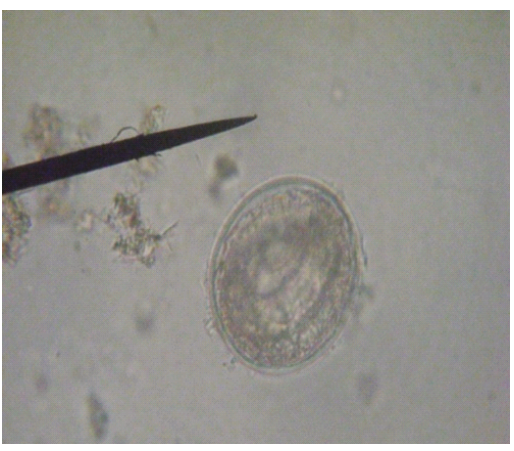

Image 1. Egg of Toxascaris leonina of Lion (720X)

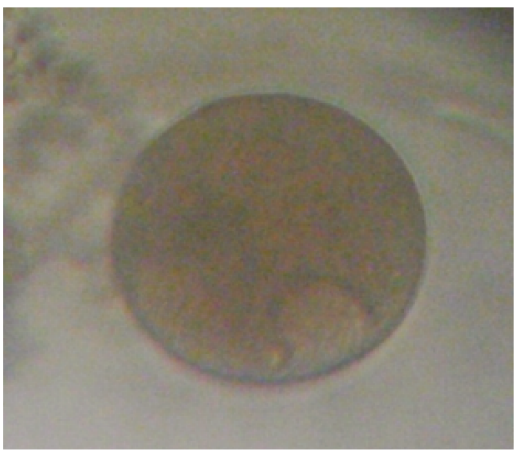

Image 4. Cyst of Balantidium coli of Hamadryads Baboon (720X)

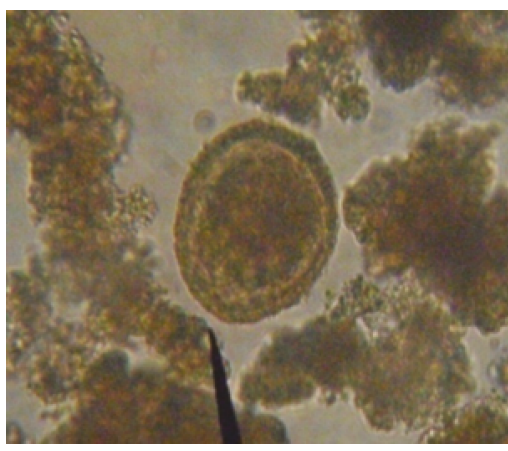

Image 2. Egg of Toxocara cati of Tiger (720X)

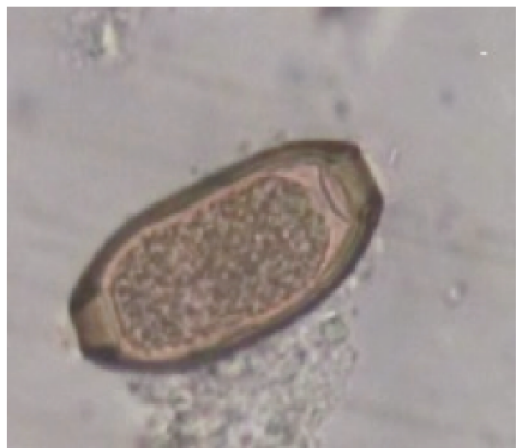

Image 5. Egg of Capillaria sp. of Common Langur(720X)

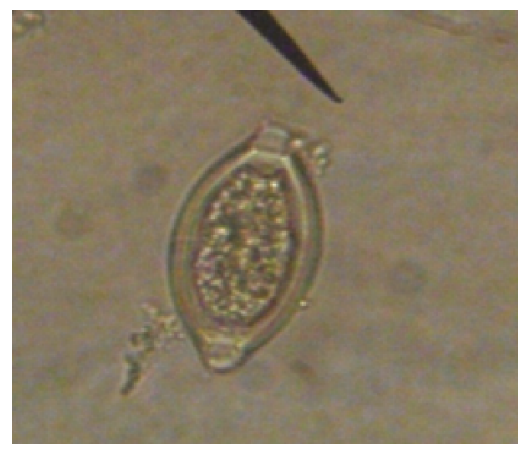

Image 3. Egg of Trichuris sp. of Rhesus Macaque (720X)

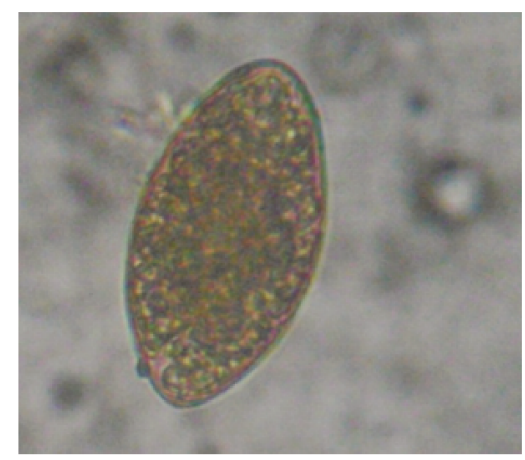

Image 6. Egg of Spirometra sp. of Indian Lion (720X) coli. This supports the findings of Fagiolini et al. (2010), who revealed Toxascaris leonina in lion. Spirometra is on the other hand a new report for captive lions in Bangladesh as to date this parasite has only been reported in wild lions, where it was found to be the most common parasite (Barutzki et al. 1985, Ghoshal et al. 1988, Tang et al. 1988, Muller-Graf 1995). However comparatively lower prevalence was recorded as $7.1 \%$ by Lim et al. (2008). The occurrence of Spirometra in this study might be due to the feeding management and the availability of intermediate hosts in the environment. Two intermediate hosts are required to complete the life cycle of Spirometra sp.; crustaceans are the first intermediate host and snakes, birds and mammals are second intermediate host (Soulsby 1982). The presence of Spirometra sp. in the lion of Dhaka Zoo might be due to ingestion of contaminated beef with infective secondary stage of larvae.

In the present study, mixed infection was observed in 12 species. Mixed parasite infections in zoo animals was recorded by Kanungo et al. (2010) and Mutani et al. (2003) found that $58.5 \%$ of all monkeys examined had at least three parasite species and only $34.0 \%$ had one and two parasite species. This suggests that there is a fairly high rate of transmission of the parasites observed between individuals either because of the monkeys' gregarious nature or because of suitable environmental conditions (Mutani et al. 2003). It has to be kept in mind however, that Mutani's study was conducted in free ranging monkeys and hence could be expected to be even lower than in a captive setting.

The finding of mixed infection in this study therefore is not surprising and might be due to the presence of all animals of different ages in the same cages, feeding management, insufficient cleaning and improper disposal of faeces.

\section{Conclusion}

Gastrointestinal parasites were prevalent in animals of this zoo. Better management practices and adequate prophylactic measures are important strategies to control gastrointestinal parasites. Further, long term epidemiological studies of parasitic infections are essential to understand infection routes and to prevent the possible recurrence of infections in captive animals at the zoo. Such studies will provide a clear concept 
regarding parasitic infection of the captive animals at Dhaka Zoo and will help to develop appropriate preventive and therapeutic measures against parasitic infection in zoo animals.

\section{References}

Barutzki, D., M.A. Hasslinger, K. Schmid \& Wiesner (1985) Situationsanalysez um Endoparasitenbefallbe i Zootieren. $T$ ierarzt liche Umschau 40: 953-961.

Cable, M.R. (1965). An illustrated Laboratory Manual of Parasitology. $5^{\text {th }}$ Edition. Burgress Publishing Company Minneapolis, USA, 5-6pp.

Chaunha, P.P.S., B. Bhatia, G.S. Arora, R.D. Agrawal \& S.S. Ahluwalia (1973). A preliminary survey of parasitic infections among mammals and birds at Lucknow and Delhi Zoo. Indian Journal of Animal Science 43(2): 163-168.

Corden, P., G.H. Prados, A. Romero, M.S. Sanchez, M. Pontes, A. Osuna \& M.J. Rosales (2008). Intestinal parasitism in the animals of the zoological garden "Pen ̃a Escrita" (Almuñecar, Spain). Veterinary Parasitology 156: 302-309.

Fagiolini, M., P.L. Riccardo, L. Piero, C. Paolo, M. Riccardo, C. Claudia, F. Riccardo \& P. Stefania (2010). Gastrointestinal parasites in mammals of two Italian zoological gardens. Journal of Zoo and Wildlife Medicine 41(4): 662-670.

Ghoshal, S.B., U.K. Garg, K.S. Misaraulia \& P.C. Jain (1988). Helminth parasites in zoo animals of Kamla Nehru Park, Indore (MP). Livestock Adviser 13: 34-36.

Gonzalez, P., E. Carbonell, V. Urios \& V.V. Rozhnov (2007). Coprology of Panthera tigris altaica and Felis bengalensis euptilurus from the Russian Far East. The Journal of Parasitology 93(4): 948-950.

Hendrix, M. \& Robinson (2006). Diagnostic Parasitology for Veterinary Technicians - $3^{\text {rd }}$ Edition. Mosby Elsevier, St. Louis, Missouri, 103 18-50.

Kanungo, S., A. Das, G.M. Das \& Shakif-ul-Azam (2010). Prevalence of gastro-intestinal helminthiasis in captive deer of Bangladesh. Wayamba Journal of Animal Science 2: 42-45.

Kimberley, A.P., E.H. Meghan, W.G. Brian \& Y. Mirtha (2004). Survey of the gastrointestinal parasites of the primate community at Tambopata National Reserve, Peru. Journal of Zoology 264: 149151.

Kumar, A., L.D. Singla, G.S. Singla, Aulakh \& J. Singh (2005). Management of piperazine resistance toxocariosis with ivermectin in lion (Panthera leo). Journal of Parasitic Diseases 29(2): 156-160

Leveck, B., P.G.T. Dorny, F. Vercammen \& J. Vereronysse (2007). Gastrointestinal protozoa in non- human primates of four zoological gardens in Belgium. Veterinary Parasitology 148: 236-246.

Lim, Y.A.L., R. Ngui, J. Shukri, M. Rohela \& N.H.R. Mat (2008).
Intestinal parasites in various animals at a zoo in Malaysia. Veterinary Parasitology 157: 154-159.

Muller-Graf, C.D. (1995). A coprological survey of intestinal parasites of wild lions (Panthera leo) in the Serengeti and the Ngorongoro Crater. The Journal of Parasitology 81(5): 812-814.

Muoria, P.K., P. Muruthi, D. Rubenstein, N.O. Oguge \& E. Munene (2005). Cross-sectional survey of gastro-intestinal parasites of Grevy's Zebras in southern Samburu, Kenya. African Journal of Ecology 43: 392-395.

Mutani, A., R. Kamara \& B. Gabriel (2003). A preliminary investigation on the gastrointestinal helminths of the Barbados Green Monkey, Cercopithecus aethiops sabaeus. Journal of the Institute of Tropical Medicine of São Paulo 45(4): 193-195.

Opara, M.N., C.T. Osuji \& J.A. Opara (2010). Gastrointestinal parasitism in captive animals at the zoological garden, Nekede Owerri, southeast Nigeria. Report and Opinion 2(5): 21-28.

Parasani, H.R., R.R. Momin, M.G. Maradin \& S. Veer (2001). A survey of gastrointestinal parasites of captive animals at Rajkot Munipical Corporation Zoo, Rajkot, Gujarat. Zoo's Print Journal 16(10): 604606; http://dx.doi.org/10.11609/JoTT.ZPJ.16.10.604-6

Rao, A.T. \& L.N. Acharjyo (1984). Diagnosis and classification of common hoofed wild life in North America. Mid American Agriculture Research in Veron, WI 53593. www.midamericaagresearch.net / document/ wildlife\%20monograph.

Singh, P., L.D. Singla, M.P. Gupta, S. Sharma, \& D.R. Sharma (2009). Epidemiology and chemotherapy of parasitic infections in wild omnivores in the Mechendra Choudhury Zoological park, Chhat Bir, Punjab. Journal of Threatened Texa 1(1): 62-64; http://dx.doi. org/10.11609/JoTT.o1767a.62-4

Singh, P., M.P. Gupta, L.D. Singla, N. Singh, \& D.R. Sharma (2006). Prevalence and chemotherapy of gastrointestinal helminth infections in wild omnivores in the Mechendra Choudhury Zoological park, Chhat Bir, Punjab. Journal of Veterinary Parasitology 20: 17-24.

Soulsby, E.J.L. (1982). Helminths, Arthopods and Protozoa of Domesticated Animals - $7^{\text {th }}$ Edition. Bailliere and Tindal, London, 766-771pp.

Stuart, M.D., L.L. Greenspan, K.E. Glander \& M.R. Clark (1990). A coprological survey of parasites of wild mantled Mowling Monkeys (Alouatta paplliata palliate). Journal of Wildlife Disease 26: 547549.

Tang, L.Z., J.L. Jin \& K. Tan (1988). Investigation of helminths in carnivorous animals in Lanzhou Wuquan Zoo. Chinese Journal of Veterinary Science and Technology 12: 20-21.

Varadharajan, A. \& C. Pythal (1999). A preliminary investigation on the parasites of wild animals at the zoological garden, Thiruvananthaparam Kerala. Zoos Print Journal 14(12): 159-164; http://dx.doi.org/10.11609/JoTT.ZPJ.14.12.159-64

Zasityte, R. \& T. Grikienciene (2002). Some data in endoparasites of common mole in Lithnani. Act Zoological Lituanica 4(12): 403 